\title{
ÉPOCA DE COLHEITA E DESENVOLVIMENTO VEGETATIVO DE AVEIA PRETA
}

\author{
Claudia Antonia Vieira Rossetto ${ }^{1,3 *}$; João Nakagawa ${ }^{2,3}$ \\ ${ }^{1}$ Depto. de Fitotecnia - UFRRJ/IA, C.P. 74511 - CEP: 23851-970 - Seropédica, RJ. \\ ${ }^{2}$ Depto. de Produção Vegetal - UNESP/FCA, C.P. 237 - CEP:18603-970 - Botucatu, SP. \\ Bolsista CNPq. \\ *Autor correspondente <cavrosse@ufrrj.br>
}

\begin{abstract}
RESUMO: Embora a aveia preta apresente importantes características de interesse agronômico, os estudos direcionados ao conhecimento da planta visando aumentos de produtividade são ainda em pequeno número em condições brasileiras. Este trabalho teve por objetivo avaliar o desenvolvimento de plantas de aveia preta, cultivar Comum. O experimento foi instalado no mês de maio, em condições de campo, em Nitossolo Vermelho, em Botucatu, SP. O delineamento experimental empregado foi inteiramente casualizado, com três repetições. Os tratamentos constaram de épocas de coletas de plantas, as quais foram iniciadas aos 21 dias após a emergência das plântulas (DAE). O maior desenvolvimento vegetativo das plantas, considerando-se o número total de perfilhos e o número total de folhas, foi observado na fase de emissão da panícula, aos 84 DAE. A contribuição dos perfilhos primários foi maior que a dos perfilhos secundários, tanto nos componentes vegetativos como nos componentes relacionados à produção de sementes.
\end{abstract}

Palavras-chave: Avena strigosa, ciclo cultural, perfilhos

\section{HARVESTING TIME AND VEGETATIVE DEVELOPMENT OF BLACK OATS}

\begin{abstract}
In spite of the fact that black oat presents important traits of agronomic interest, studies addressed to productivity are still in small number for Brazilian conditions. One experiment was carried under field conditions, at Botucatu, SP, Brazil, to study the plant development of Avena strigosa Schreb cv. Comum, grown on a Rhodic Nitisol. The experiments followed a completely randomized block design with three replications. The treatments consisted of weekly harvests, starting 21 days after sowing. Plant characteristics were evaluated at each harvesting time. The highest development of plant was observed at 84 days after sowing, when the panicle emergence started. There was a higher contribution of primary tillers in relation to secondary for the vegetative development and yield components.

Key words: Avena strigosa, crop cycle, tillers
\end{abstract}

\section{INTRODUÇÃO}

A aveia preta é gramínea utilizada como forrageira de inverno, para pastejo direto ou conservação na forma de feno ou silagem (Salerno \& Vetterle, 1984; Rossetto \& Nakagawa, 1995a). Segundo Pereira (1985), a aveia preta tem sido destinada ao manejo e conservação do solo, como cobertura do solo e como adubação verde (Derpsch et al., 1985; Floss \& Ceccon,1998) ou para a semeadura direta, por ser produtora de grande quantidade de massa, de decomposição mais lenta que as leguminosas empregadas como adubo verde (Nakagawa et al., 1994). No entanto, para Santos (1991), essa característica dificulta o estabelecimento da soja em plantio direto, principalmente sob períodos de baixa precipitação pluvial, logo após a colheita das aveias, devido à menor taxa de decomposição dos restos culturais nessas condições.

Essa gramínea cresce e se desenvolve rapidamente, auxiliando no controle de erosão e das plantas daninhas (Almeida \& Rodrigues, 1985). Do ponto de vista fitopatológico, é resistente ao mal-do-pé (Gaeumannomyces graminis var. tritici) e à prodridão comum (Bipolaris sorokiniana) em comparação com outras gramíneas, podendo ser utilizada com vantagens em sistemas de cultivo com a cevada e com o trigo (Fontaneli \& Piovezan, 1991; Reis et al., 1992; Santos \& Reis, 1994).

Apesar destas importantes características, de interesse agronômico, apresentadas pela aveia preta, estudos direcionados ao melhor conhecimento da planta são ainda em pequeno número, em condições brasileiras (Rossetto \& Nakagawa, 1995b). Em aveia, estudos do desenvolvimento da planta têm sido realizados (Kaufman \& Brock, 1992; Peterson, 1992; White, 1995; Brouwer \& Flood, 1995) mas necessitam de muitas outras pesquisas nesta área para se obter maiores aumentos de produtividade (Peterson, 1992; Brouwer \& Flood, 1995).

O objetivo do presente trabalho foi o de avaliar o desenvolvimento de plantas de aveia preta, cultivar Comum, por meio de experimento instalado no mês de maio, em condições de Botucatu - SP. 


\section{MATERIAL E MÉTODOS}

O experimento com plantas de aveia-preta (Avena strigosa Schreb), cultivar Comum, foi conduzido em condições de campo, no ano de 1987, em solo classificado como Terra Roxa Estruturada distrófica, textura argilosa (Carvalho et al., 1983), nomeado como Nitossolo Vermelho, por EMBRAPA (1999), pertencente à Fazenda Experimental Lageado (FEL) da UNESP, localizada no município de Botucatu, $\mathrm{SP}$, com altitude de $815 \mathrm{~m}$, latitude de $22^{\circ} 51^{\prime} \mathrm{S}$, longitude de $48^{\circ} 26^{\prime} \mathrm{WGrw}$ e clima mesotérmico de inverno seco. Os dados de precipitação pluvial e temperaturas máxima e mínima do ar foram obtidos no Posto Meteorológico da FEL e estão apresentados na FIGURA 1.

O delineamento experimental utilizado foi inteiramente casualizado, com três repetições. As plantas foram coletadas em seis épocas, a partir de 21 dias após a emergência das plântulas (DAE), com intervalos de 21 dias entre as épocas de coleta.

A adubação realizada na semeadura em área total, foi feita com base nas recomendações encontradas nas Instruções Agrícolas para o Estado de São Paulo (Instituto Agronômico, 1986), para aveia (Avena sativa $\mathrm{L})$, empregando-se $10 \mathrm{~kg} \mathrm{ha}^{-1} \mathrm{de} \mathrm{N}, 60 \mathrm{~kg} \mathrm{ha}^{-1} \mathrm{de} \mathrm{P}_{2} \mathrm{O}_{5} \mathrm{e}$ $40 \mathrm{~kg} \mathrm{ha}^{-1} \mathrm{de} \mathrm{K}_{2} 0$, nas formas de sulfato de amônio, superfosfato simples e cloreto de potássio, respectivamente.

A semeadura foi realizada manualmente, em sete de maio, empregando-se a densidade de 30 sementes por metro, com espaçamento entre linhas de $0,20 \mathrm{~m}$. A emergência das plântulas foi constatada aos 18 de maio. Os tratos culturais, que constaram de capinas e adubação de cobertura com $30 \mathrm{~kg} \mathrm{ha}^{-1}$ de nitrogênio, na forma de sulfato de amônio, foram realizados em torno de 30 dias após a semeadura.
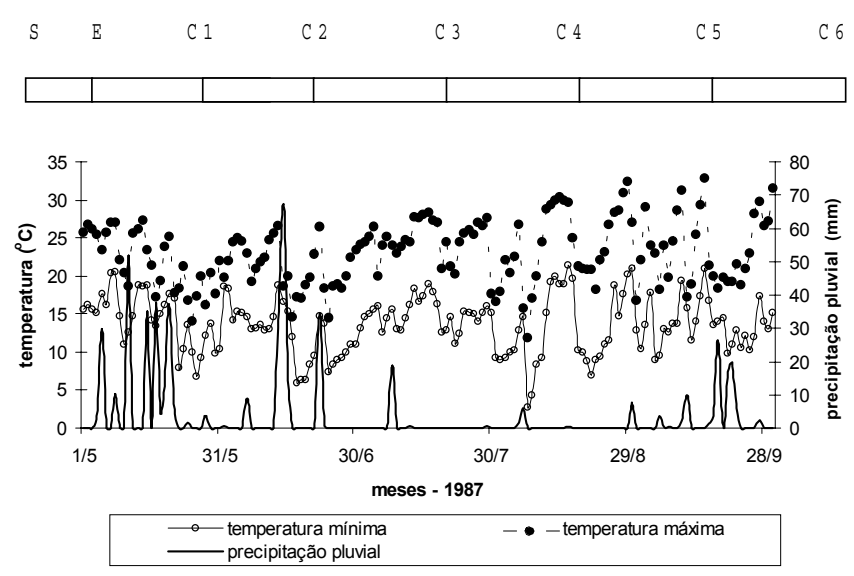

Figura 1 - Temperatura máxima (•) e mínima (•) do ar e precipitação pluvial, registrados no Posto Meteorológico da Fazenda Experimental Lageado, no período de 01/05/87 a 30/091/ 87 e, épocas de colheita de sementes de aveia preta ( $S=$ semeadura; $E=$ =emergência de plântulas e $\mathrm{C} 1$ a $\mathrm{C} 6=$ coletas).
Em cada época de coleta, foi avaliado o número de plantas $\mathrm{m}^{-2}$ e, em seguida, foram coletadas as plantas de $0,5 \mathrm{~m}$ em linha contínua de cada repetição. Estas plantas foram levadas para o laboratório, acondicionadas em sacos de plástico, para avaliação de altura da planta $(\mathrm{cm})$; número de perfilhos primários, secundários e total; número de perfilhos úteis primários, isto é, aqueles com panícula; número de perfilhos úteis secundários; percentagem de perfilhos primários úteis; percentagem de perfilhos secundários úteis; número médio de folhas da haste principal e das hastes dos perfilhos primários, secundários e total; número de folhas das hastes dos perfilhos primário (de ordem de 1 a 5) e dos secundários (de ordem de 1 a 7 ); número médio de sementes por panícula da haste principal, dos perfilhos primários e secundários, e peso de matéria seca de 1000 sementes das panículas da haste principal e dos perfilhos primários e secundários. Estes dados foram expressos por planta.

Foram obtidos os índices de área foliar das hastes principal, das dos perfilhos primários e secundários, e total; a área foliar foi avaliada empregando-se o medidor de área foliar e expressa em centímetros quadrados.

Os resultados foram submetidos à análise de variância. As variáveis em percentagem e em número, foram transformadas, prévia e respectivamente, em arco seno da raiz quadrada da percentagem e em raiz quadrada do número. As médias foram comparadas pelo teste de Tukey, a $5 \%$. As equações foram ajustadas pela análise de regressão polinomial. A seleção da função de melhor ajuste obedeceu ao maior coeficiente de correlação, complementado com a expectativa biológica.

\section{RESULTADOS E DISCUSSÃO}

O número médio de plantas $\mathrm{m}^{-2}$ não apresentou diferenças significativas no decorrer das coletas, obtendo-se na média destas, 126 plantas $\mathrm{m}^{-2}$.

A altura das plantas de aveia preta foi crescente desde a primeira (21 DAE) até a sexta coleta, realizada aos 126 DAE (Figura 2). Por estes resultados, verifica-se que, o aumento da altura da planta ficou bem caracterizado por uma equação do segundo grau (Figura 2 ), tornando-se o crescimento menos evidente após a emissão das panículas, que foi observada na quarta coleta (84 DAE). Em aveia, o crescimento em altura da planta é mais acentuado no período que antecede a emergência da panícula (White, 1995), em função do maior crescimento dos três ou quatro internódios superiores e do pedúnculo (Peterson, 1992; White, 1995). Neste experimento, verifica-se que as plantas apresentaram bom crescimento, provavelmente, devido a maior precipitação pluvial ocorrida na fase inicial da cultura.

O número de perfilhos primários (produzidos na axila das folhas da haste principal) aumentou até a quarta coleta (84 DAE), ocasião em que já havia emissão 
da panícula (Figura 2). Na aveia, a formação dos perfilhos cessa com o início do desenvolvimento da panícula. Todavia, para algumas cultivares, estas estruturas podem formar-se mesmo após a emergência da panícula (Brouwer \& Flood, 1995). A maior precipitação pluvial ocorrida até a segunda coleta (Figura 1), certamente possibilitou a maior formação dos perfilhos primários nesta fase.

Os perfilhos secundários (produzidos nas axilas das folhas dos perfilhos primários) começaram a surgir a partir da primeira coleta (21 DAE) e aumentaram até a quarta coleta (84 DAE), à semelhança dos perfilhos primários, porém em menor número (Figura 2).

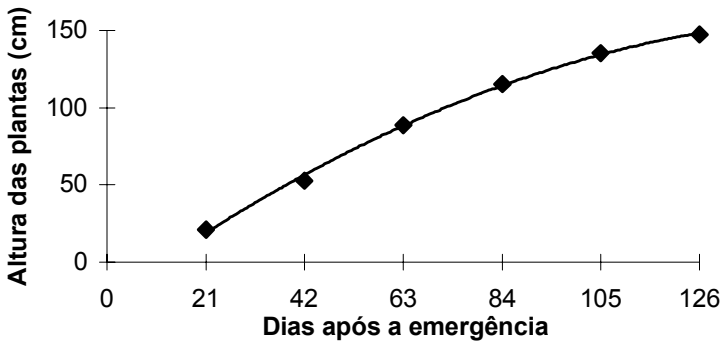

$y=-0,0066 x^{2}+2,3441 x-47,332 R 2=0,9979 * *$

) haste principal

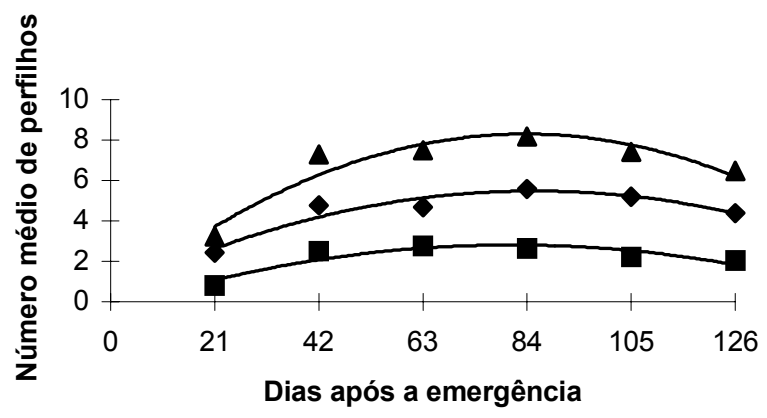

( ) $\mathrm{y}=-0,0007 \mathrm{x}^{2}+0,131 \mathrm{x}-0,7693 \mathrm{R} 2=0,906^{*}$

(a) $\mathrm{y}=-0,0005 \mathrm{x}^{2}+0,0882 \mathrm{x}-1,193 \mathrm{R} 2=0,8186^{*}$

(A) $\mathrm{y}=-0,0012 \mathrm{x}^{2}+0,2191 \mathrm{x}-1,96 \mathrm{R} 2=0,903 *$

$(\diamond)$ Perfilho primário (অ) Perfilho secundário ( $\mathbf{\Delta})$ total

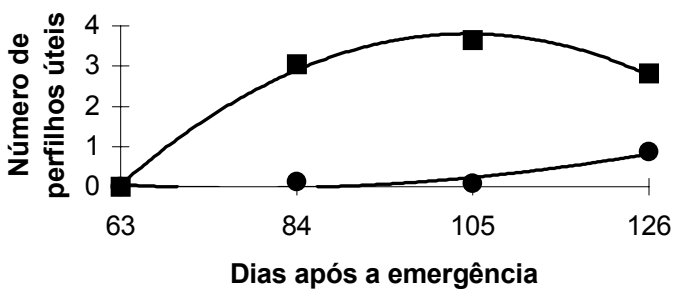

(ש) $\mathrm{y}=-0.0022 \mathrm{x}^{2}+0.458 \mathrm{x}-20.127 \mathrm{R} 2=0.9974 * *$

(•) $\mathrm{y}=0.0004 \mathrm{x}^{2}-0.0585 \mathrm{x}+2.253 \mathrm{R} 2=0.8935$ *

(ロ ) Perfilho primário (• ) Perfilho secundário

Figura 2 - Altura, número médio de perfilhos primários, secundários e total por planta, número médio de perfilhos úteis primários, secundários e total, por planta de aveia preta cultivada em 1987. Botucatu, SP.
O número total de perfilhos seguiu a mesma tendência de aumento observado para os perfilhos primários e secundários, tendo-se a maior contribuição devido aos perfilhos primários (Figura 2). A partir da emissão das panículas (84 DAE), a situação observada foi a de diminuição do número de perfilhos, devido a senescência destes. Isto ocorreu porque na planta há uma hierarquia de tamanho de perfilhos estabelecida pela idade, onde os mais velhos por serem os maiores, têm melhores condições de sobreviver que os mais novos, que tendem a perecer, por serem os menores (White, 1995). No presente trabalho, a baixa precipitação pluvial no período (Figura 1) deve ter contribuído para esta senescência dos perfilhos menores. Desta forma, a época da emissão da panícula, quando se obtém o maior valor em termos de total de perfilhos, é o momento mais adequado de utilização da aveia preta, quando se deseja aproveitar o maior desenvolvimento vegetativo como fitomassa, para cobertura de solo, concordando com Medeiros (1998) e Rosa \& Ender (1998). Foram observadas plantas com até dez perfilhos primários e sete perfilhos secundários, demonstrando a grande capacidade de perfilhamento apresentada por esta espécie, o que justifica a sua utilização como forragem e como adubação verde (Salerno \& Vertterle, 1984; Derpsch et al., 1985).

O número de perfilhos úteis (com panícula) foi crescente da terceira coleta (64 DAE) até a quinta (105 DAE) (Figura 2), para a seguir estabilizar-se. Os perfilhos úteis secundários, em menor número e que surgem mais tardiamente, foram crescentes até a última coleta (Figura 2). Este aumento no número das panículas (perfilhos úteis) no decorrer das coletas é resultante da seqüência da produção de perfilhos, em sincronia com o surgimento das folhas e do crescimento, que depende das condições do ambiente, sendo que somente uma certa proporção dos perfilhos produz panículas (White, 1995).

Ao considerar-se a percentagem de perfilhos úteis, ou seja, o percentual de perfilho que originou panícula (Figura 3), verifica-se que nem todos perfilhos (Figura 2) originaram perfilhos úteis, tanto para os primários, como principalmente para os secundários. Brouwer \& Flood (1995) relatam que, em aveia, um alto número de perfilhos não é interessante porque são poucos os perfilhos secundários a originarem panículas produtivas, como observado neste experimento. Observa-se que a percentagem de perfilhos úteis aumentou até a última coleta (Figura 3 ), apesar do número ter-se estabilizado antes, em função da diminuição do número de perfilho total.

O número médio de folhas da haste principal foi crescente até quarta coleta (Figura 3), ou seja, até a emissão da panícula (84 DAE). Após atingir os valores máximos, ocorreu decréscimo em função da senescência das folhas mais velhas, conforme também observado por White (1995). 
Os aumentos dos números médios das folhas dos perfilhos primários e secundários ocorreram até as coletas posteriores à emissão da panícula principal (84 DAE) (Figura 3). Isto mostra que na aveia preta, o desenvolvimento dos perfilhos continua com a formação de novas folhas, mesmo após a emergência das panículas da haste principal, sendo mais acentuado o desenvolvimento dos perfilhos secundários. Fazendo-se uma análise mais detalhada

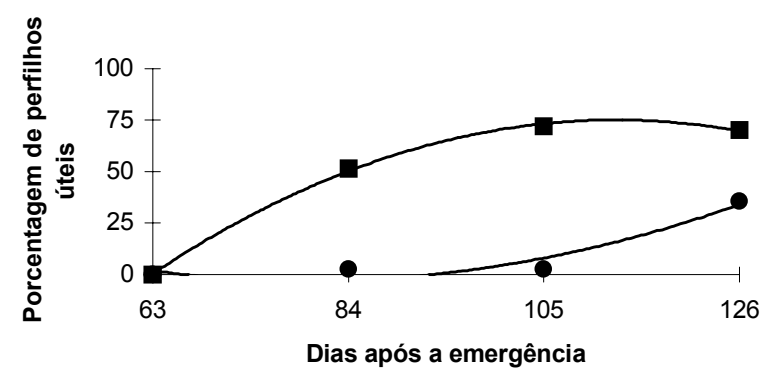

(ש) $\mathrm{y}=-0.0302 \mathrm{x}^{2}+6.809 \mathrm{x}-308.7 \mathrm{R} 2=0.999 * *$

(•) $\mathrm{y}=-0.0173 \mathrm{x}^{2}-2.7543 \mathrm{x}+106.73 \mathrm{R} 2=0.9279 * *$

(ם) Perfilho primário (•) Perfilho secundário

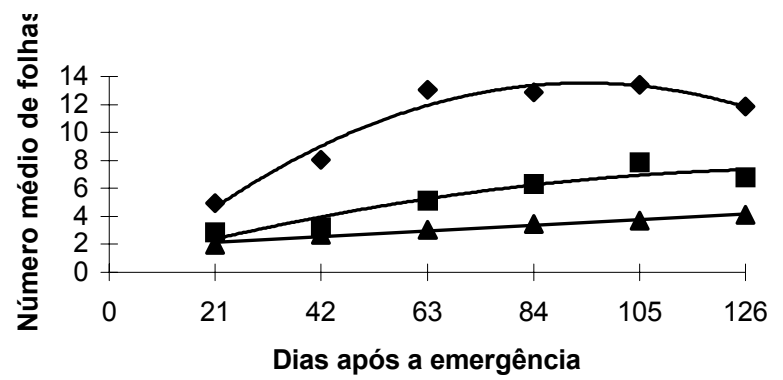

(४) $\mathrm{y}=-0,0017 \mathrm{x}^{2}+0,3468 \mathrm{x}-4,5067 \mathrm{R} 2=0,9571 *$

(a) $\mathrm{y}=-0,0003 \mathrm{x}^{2}+0,1033 \mathrm{x}-0,4941 \mathrm{R} 2=0,9025^{*}$

(A) $\mathrm{y}=0,0195 \mathrm{x}+1,7227 \mathrm{R} 2=0,9804 * *$

$(\bullet$ ) Haste principal ( $\boldsymbol{\square}$ ) Perfilho primário ( $\boldsymbol{\Delta}$ ) perfilho secundário

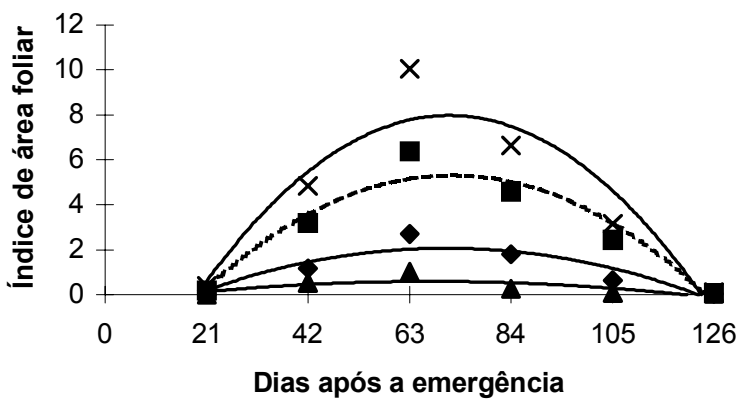

(४) $\mathrm{y}=-0,0008 \mathrm{x}^{2}+0,1072 \mathrm{x}-1,7174 \mathrm{R} 2=0,8242$ n.s.

(ש) $\mathrm{y}=-0,0019 \mathrm{x}^{2}+0,2798 \mathrm{x}-4,7599 \mathrm{R} 2=0,9147$ *

(•) $\mathrm{y}=-0,0002 \mathrm{x}^{2}+0,0291 \mathrm{x}-0,385 \mathrm{R} 2=0,5301$ n.s.

(x) $y=-0,0029 x^{2}+0,4169 x-6,8788 R 2=0,8702 *$

(४) haste principal (ם ) Perfilho primário

(•) Perfilho secundário $(\mathrm{x})$ total

Figura 3 - Percentagem de perfilhos úteis por planta, número médio de folhas por planta e índice de área foliar por planta de aveia preta cultivada em 1987. Botucatu,SP. do número de folhas dos perfilhos primários e secundários, em função da ordem de surgimento (TABELA 1), constata-se que, para todos os perfilhos, o número de folhas foi crescente até em torno do surgimento da panícula da haste principal ou na coleta seguinte (105 DAE) e que o número de folhas foi menor quando de ordem mais avançada do perfilho, mostrando o sincronismo neste surgimento de folhas e de perfilhos.

O número total de folhas da planta de aveia preta foi crescente até 105 DAE (TABELA 1), seguindo-se da redução deste número na coleta posterior. A redução do número de folhas, foi também observada por Godoy et al. (1990) e por Reis et al. (1992) e, é resultado da senescência das folhas mais velhas no decorrer das coletas.

$\mathrm{Na}$ avaliação do índice de área foliar (Figura 3), as plantas coletadas aos 63 DAE (terceira coleta) apresentavam maior valor de IAF total e de todos os demais IAF avaliados separadamente, isto porque as folhas, embora em menor número nesta época (Figura 3 , TABELA 1), encontravam-se todas verdes. Nas coletas seguintes, houve decréscimos dos IAF, resultante da senescência natural e, em parte forçada ou antecipada, pela menor precipitação pluvial (Peterson, 1992) entre as coletas terceira e quarta (Figura 1). De acordo com Simmons (1987), em trigo, o máximo de área foliar por planta é obtido quando se tem a máxima expansão da folha bandeira, que ocorre um pouco antes da emergência da panícula. Nesta fase, se tivesse ocorrido precipitação pluvial, provavelmente, o IAF da aveia preta teria sido maior por ocasião da máxima expansão da folha bandeira, pela manutenção de maior número de folhas verdes.

Na quarta coleta (84 DAE), havia emissão de panícula da haste principal e dos perfilhos primários e secundários (TABELA 2), embora ainda não fosse em todas as plantas. $O$ número médio de sementes por panícula da haste principal aumentou da quarta coleta (84 DAE) para as seguintes (TABELA 2), até atingir um máximo. Nas primeiras coletas, algumas panículas apresentavam sementes formadas apenas no ápice, vindo a explicar os aumentos progressivos do número de sementes observados. Pode-se verificar que o número de sementes foi maior na panícula da haste principal, seguindo-se das panículas dos perfilhos primários e dos perfilhos secundários. As maiores diferenças observadas foram entre o número de sementes da panícula da haste principal e da do perfilho secundário.

O peso de matéria seca de 1000 sementes das panículas da haste principal e dos perfilhos primários e secundários foi aumentando no decorrer das coletas (TABELA 2), a partir da quarta (84 DAE), até atingir um valor máximo, na última coleta, tendo-se as sementes dos perfilhos secundários menores valores de peso que as da haste principal e as dos perfilhos primários. 
TABELA 1 - Número de folhas do perfilho primário (de ordem 1, 2, 3, 4 e 5), do perfilho secundário (de ordem 1, 2, 3, 4, 5, 6 e 7) e total de folhas da haste principal e das hastes dos perfilhos das plantas de aveia preta cultivada no ano de 1987. Botucatu. SP.

\begin{tabular}{|c|c|c|c|c|c|c|c|c|c|c|c|c|c|}
\hline \multirow{2}{*}{$\mathrm{DAE}^{*}$} & \multicolumn{5}{|c|}{ Número de folha do perfilho primário } & \multicolumn{7}{|c|}{ Número de folha do perfilho secundário } & \multirow{2}{*}{$\begin{array}{c}\text { Número } \\
\text { total }\end{array}$} \\
\hline & 1 & 2 & 3 & 4 & 5 & 1 & 2 & 3 & 4 & 5 & 6 & 7 & \\
\hline 21 & $2,61 c^{1}$ & $2,73 d$ & $1,21 \mathrm{c}$ & $0,35 \mathrm{~b}$ & $0,00 \mathrm{~b}$ & $0,89 \mathrm{~b}$ & $0,53 \mathrm{~b}$ & $0,21 \mathrm{a}$ & $0,00 \mathrm{a}$ & $0,00 \mathrm{a}$ & $0,00 \mathrm{a}$ & $0,00 \mathrm{a}$ & $13,47 d$ \\
\hline 42 & $3,15 \mathrm{c}$ & $3,03 d$ & $2,89 \mathrm{~b}$ & $2,42 a b$ & $1,48 a b$ & $2,04 a b$ & $1,71 a b$ & $1,49 a$ & $0,82 \mathrm{a}$ & $0,60 \mathrm{a}$ & $0,08 \mathrm{a}$ & $0,00 \mathrm{a}$ & $30,04 \mathrm{c}$ \\
\hline 63 & $5,15 b$ & $4,80 \mathrm{c}$ & $4,61 \mathrm{ab}$ & $3,79 a b$ & $2,30 a b$ & $2,44 a b$ & $2,43 a$ & $1,60 \mathrm{a}$ & $1,14 \mathrm{a}$ & $0,39 a$ & $0,34 \mathrm{a}$ & $0,18 a$ & $45,31 \mathrm{~b}$ \\
\hline 84 & $6,35 \mathrm{~b}$ & $6,43 a b$ & $6,10 \mathrm{a}$ & $5,53 \mathrm{a}$ & $4,13 a$ & $2,98 a b$ & $2,02 a b$ & 1,63 a & $1,10 \mathrm{a}$ & $0,73 a$ & $0,50 \mathrm{a}$ & $0,67 \mathrm{a}$ & $56,96 \mathrm{a}$ \\
\hline 105 & 7,87 a & $7,78 \mathrm{a}$ & $6,98 a$ & $5,04 \mathrm{a}$ & $4,27 a$ & $2,72 a b$ & $2,63 a$ & $1,90 \mathrm{a}$ & $0,66 \mathrm{a}$ & $0,16 \mathrm{a}$ & $0,21 \mathrm{a}$ & $0,00 \mathrm{a}$ & $62,37 \mathrm{a}$ \\
\hline 126 & $6,81 a b$ & $5,84 \mathrm{bc}$ & $5,89 a$ & $3,47 a b$ & $2,62 a b$ & $3,88 a$ & $2,50 \mathrm{a}$ & $1,33 \mathrm{a}$ & $0,42 a$ & $0,21 \mathrm{a}$ & $0,08 \mathrm{a}$ & $0,00 \mathrm{a}$ & $50,19 \mathrm{~b}$ \\
\hline C.V.(\%) & 5,21 & 4,36 & 8,10 & 23,99 & 27,19 & 14,51 & 14,36 & 26,35 & 35,03 & 27,08 & 23,20 & 27,15 & 14,30 \\
\hline
\end{tabular}

* DAE - dias após a emergência das plântulas.

${ }^{1}$ Médias seguidas das mesmas letras não diferem a $5 \%$, pelo teste de Tukey.

TABELA 2 - Número médio de sementes por panícula e peso médio de matéria seca de 1000 sementes das panículas da haste principal e dos perfilhos primário e secundário das plantas de aveia preta cultivadas no ano de 1987. Botucatu, SP.

\begin{tabular}{lccc}
\hline \multirow{2}{*}{ AE* $^{*}$} & \multicolumn{3}{c}{ Número de sementes por panícula } \\
\cline { 2 - 4 } & Haste principal & Perfilho primário & Perfilho secundário \\
\hline 21 & $0.00 \mathrm{c}$ & $0.00 \mathrm{c}$ & $0.00 \mathrm{~b}$ \\
42 & $0.00 \mathrm{c}$ & $0.00 \mathrm{c}$ & $0.00 \mathrm{~b}$ \\
63 & $0.00 \mathrm{c}$ & $0.00 \mathrm{c}$ & $0.00 \mathrm{~b}$ \\
84 & $47.84 \mathrm{~b}$ & $15.59 \mathrm{~b}$ & $3.33 \mathrm{~b}$ \\
105 & $71.35 \mathrm{ab}$ & $53.38 \mathrm{a}$ & $10.32 \mathrm{ab}$ \\
126 & $83.43 \mathrm{a}$ & $57.05 \mathrm{a}$ & $40.60 \mathrm{a}$ \\
\hline C.V.(\%) & 15.02 & 20.62 & 50.14 \\
\hline \multirow{2}{*}{ DAE* } & Pe so de matéria seca de & 1000 se mentes \\
\cline { 2 - 4 } & Haste principal & Perfilho primário & Perfilho secundário \\
\hline 21 & $0.00 \mathrm{~d}$ & $0.00 \mathrm{~d}$ & $0.00 \mathrm{~b}$ \\
42 & $0.00 \mathrm{~d}$ & $0.00 \mathrm{~d}$ & $0.00 \mathrm{~b}$ \\
63 & $0.00 \mathrm{~d}$ & $0.00 \mathrm{~d}$ & $0.00 \mathrm{~b}$ \\
84 & $4.06 \mathrm{c}$ & $3.50 \mathrm{c}$ & $0.75 \mathrm{~b}$ \\
105 & $11.63 \mathrm{~b}$ & $9.58 \mathrm{~b}$ & $4.24 \mathrm{~b}$ \\
126 & $17.58 \mathrm{a}$ & $17.70 \mathrm{a}$ & $16.73 \mathrm{a}$ \\
\hline C.V.(\%) & 7.70 & 6.88 & 31.96 \\
\hline
\end{tabular}

*DAE - dias após a emergência das plântulas.

${ }^{1}$ Médias seguidas das mesmas letras não diferem a $5 \%$, pelo teste de Tukey.

A contribuição esperada dos perfilhos primários na produção de sementes é grande, pois além de serem em maior número e com maior percentual de perfilhos com panícula, o número de sementes formadas por panícula e o peso destas pouco diferem dos valores da panícula da haste principal; em contrapartida, a contribuição dos perfilhos secundários deve ser pequena, pois são em menor número, com menor percentual de perfilhos úteis (com panículas), e suas panículas com número e peso de sementes menor que os das panículas da haste principal e dos perfilhos primários.

\section{REFERÊNCIAS BIBLIOGRÁFICAS}

ALMEIDA, F.S.; RODRIGUES, B.N. Guia de herbicidas, contribuição para o uso adequado em plantio direto e convencional. Londrina: IAPAR, 1985. 482p.

BROUWER, J.; FLOOD, R.G. Aspects of oat physiology. In: WELCH, R.W. (Ed.) The oat crop: production and utilization. London: Chapman \& Hall, 1995. p.177-222.

INSTITUTO AGRONÔMICO. Instruções agrícolas para o Estado de São Paulo. 3.ed. Campinas: IAC, 1986. 229p. (Boletim, 200).

CARVALHO, W.A.; ESPINDOLA, C.R.; PACCOLA, A.A. Levantamento de solos da Fazenda Lageado. Botucatu: FCA/UNESP, 1983. 95p. (Boletim Técnico,1).

DERPSCH, R.; SIDIRAS, N.; HEINZMANN, F.Z. Manejo do solo em coberturas verdes de inverno. Pesquisa Agropecuária Brasileira, v.20, p.761-773, 1985.

EMPRESA BRASILEIRA DE PESQUISA AGROPECUÁRIA. Centro Nacional de Pesquisa de Solos. Sistema brasileiro de classificação de solos. Brasília: Embrapa Produção de Informação; Rio de Janeiro: Embrapa Solos, 1999. 412p.

FLOSS, E.L.; CECCON, G. Ensaio regional de aveias pretas, em Passo Fundo, 1997. In: REUNIÃO DA COMISSÃO BRASILEIRA DE PESQUISA DE AVEIA, 18., Londrina, 1998. Resumos. Londrina: IAPAR, 1998. p.376-378.

FONTANELI, R.S.; PIOVEZAN, A.J. Efeito de cortes no rendimento de forragem e grãos de aveia. Pesquisa Agropecuária Brasileira, v.26, p.691-697, 1991.

GODOY, R.; BATISTA, L.A.R.; FLOSS, E.L.; NEGREIROS, G.F. Caracterização de cultivares de aveia forrageira em São Carlos, SP. São Carlos: Embrapa, UEPAE, 1990. 4p. (Comunicado Técnico, 4).

KAUFMAN, P.B.; BROCK, T.G. Structural development of the oat plant. In: MARSHALL, H.G.; SORAELLS, M.E. (Ed.) Oat science and technology. Madison: ASA, 1992. p.53-75.

MEDEIROS, M.C. Ensaio regional de aveia preta, Vacaria, 1997. In: REUNIÃO DA COMISSÃO BRASILEIRA DE PESQUISA DE AVEIA, 18., Londrina, 1998. Resumos. Londrina: IAPAR, 1998. p.379-381.

NAKAGAWA, J.; CAVARIANI, C.; MACHADO, J.R. Maturação de sementes de aveia preta (Avena strigosa Schreb): I. Maturidade de campo. Pesquisa Agropecuária Brasileira, v.29, p.315-326, 1994.

PEREIRA, J.P. Aveia forrageira. Informe Agropecuário, v.6, p.59-70, 1985. 
PETERSON, D.M. Physiology and development of the oat plant. In: MARSHALL, H.G.; SORRELLS, M.E. (Ed.) Oat science and technology. Madison: ASA, 1992. p.77-114.

ROSSETTO, C.A.V.; NAKAGAWA, J. Efeito da época de semeadura no desenvolvimento de plantas de aveia preta (Avena strigosa Schreb ). Científica, v.23, p.151-164, 1995a.

ROSSETTO, C.A.V.; NAKAGAWA, J. Efeito da época de semeadura na produção e qualidade de sementes de aveia preta (Avena strigosa Schreb ). Científica, v.23, p.171-184, 1995b.

REIS, R.A.; RODRIGUES, L.R. de A.; COAN, O.; RESENDE, K.T. de. Efeito de diferentes épocas de colheita sobre a produção de forragem e de sementes de aveia preta. Pesquisa Agropecuária Brasileira, v.27, p.111-117, 1992.

ROSA, J.L.; ENDER, M. Ensaio regional de aveia preta - Lages, SC - 1997. In: REUNIÃO DA COMISSÃO BRASILEIRA DE PESQUISA DE AVEIA, 18., Londrina, 1998. Resumos. Londrina: IAPAR, 1998. p.386-387.

SALERNO, A.R.; VETTERLE, C.P. Avaliação de forrageiras de inverno no Baixo Vale do Itajaí, Santa Catarina. Florianópolis: EMPASC, 1984. 2p. (Comunicado Técnico, 76).
SANTOS, H.P. Efeito de sistemas de cultivo sobre rendimento de grãos e outras características agronômicas da aveia preta e da branca, em rotação com trigo. Pesquisa Agropecuária Brasileira, v.26, p.709-714, 1991.

SANTOS, H.P.; REIS, E.M. Sistemas de cultivo de trigo com azevém e aveia preta para forragem. Pesquisa Agropecuária Brasileira, v.29, p.1571-1576, 1994.

SIMMONS, S.R. Growth, development and physiology. In: HEINS, E.G. (Ed.) Wheat and wheat improvement. 2.ed. Madison: ASA, 1987. p.77-113.

WHITE, E.M. Structure and development of oats. In: WELCH, R.W. (Ed.) The oat crop: production and utilization. London: Chapman \& Hall, 1995. p.88-119.

$\overline{\text { Recebido em } 06.06 .00}$ 